\title{
HPLC Separation of Amino Acids is Appropriate?
}

\section{Hideharu Shintani*}

School of Science, Chuo University, 1-13-27, Kasuga Bunkyo 112-0003, Tokyo, Japan

Concerning amino acid analysis, it is so often used post column derivatization method using ninhydrin or ortho-phthal aldehyde with gradient elution. Ninhydrin and ortho-phtal aldehyde are identical. Problem is that 21 sorts of amino acids cannot always baseline separation (Figure 1).

From the Figure, several sorts of amino acids are not base-line separation and require at least Rs (resolution) more than 1.5 for baseline separation. Amino acid chromatographies done by Shimazdu, Hitachi or Nihon Bunko were almost identical. They require baseline separation; otherwise reproducible determination cannot be attained. For that purpose of base-line separation, gradient elution condition must be innovated. Most innovated point is the use of column with higher theoretical plate number. So, I suppose why they do not use capillary-column with higher theoretical plate number.

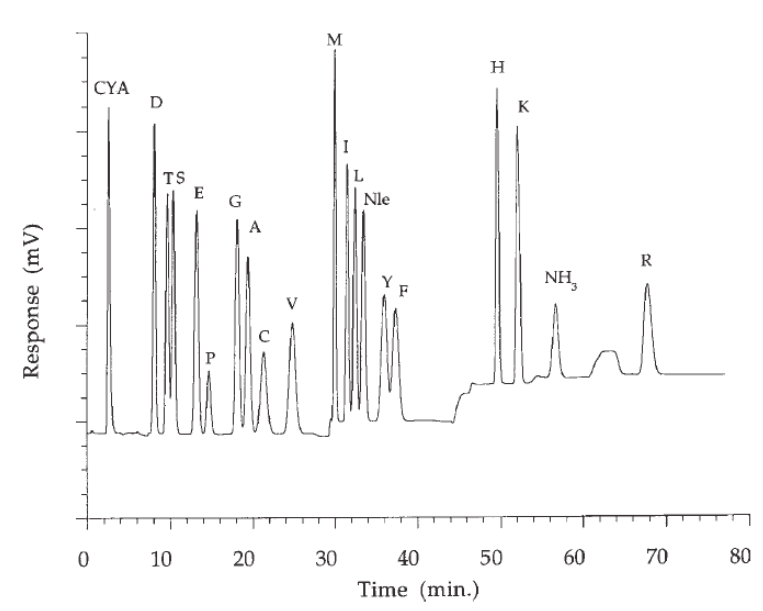

Figure 1: Several sorts of amino acids are not base-line separation and require at least $\mathrm{Rs}$ (resolution) more than 1.5 for baseline separation.
The above presented chromatogram is representative chromatogram, so analytical validation is further required and gradient condition and elution condition must be innovated to attain base-line separation chromatogram.

The separation condition obtained chromatogram is presented in Table 1.

The elution order of amino acids is from acidic amino acid, neutral amino acid. and then basic amino acid, indicating cation chromatography-column will be used. This selection is normal, but gradient condition is required innovation for base-line separation. Most of acidic amino acid and neutral amino acid are not separated in based-line. This is. further, requires analytical validation to reproducible analytical results.

\begin{tabular}{|l|l|l|}
\hline Time(min) & Event & Conditions \\
\hline 0.0 & Sample injection & Na-E buffer, $48^{\circ} \mathrm{C}$ \\
\hline 8.5 & Start temp.gradient & $48^{\circ} \mathrm{C}$ to $60^{\circ} \mathrm{C}$ in $8 \mathrm{~min}$ \\
\hline 24.5 & Buffer change & Na-E to Na-F \\
\hline 41.0 & Buffer change & Na-F to Na-D \\
\hline 78.0 & Reagent pump & Ninhydrin to water \\
\hline 79.0 & Buffer change & Na-D to $\mathrm{Na}-\mathrm{R}$ \\
\hline 80.0 & Buffer change & Na-R to $\mathrm{Na}-\mathrm{E}$ \\
\hline 82.5 & Temperature change & $60^{\circ} \mathrm{C}$ to $48^{\circ} \mathrm{C}$ \\
\hline 84.0 & Reagent pump & Water to ninhydrin \\
\hline 97.0 & Recycle (Start next run) & \\
\hline
\end{tabular}

Buffer pump: $16 \mathrm{~mL} / \mathrm{h}$

Reagent pump: $8 \mathrm{~mL} / \mathrm{h}$

Table 1: Standard amino acid analysis.
*Corresponding author: Hideharu Shintani, School of Science, Chuo University, 1-13-27, Kasuga Bunkyo 112-0003, Tokyo, Japan, Tel: +81425922336; E-mail: shintani@mail.hinocatv.ne.jp

Received November 16, 2013; Accepted November 19, 2013; Published November 22, 2013

Citation: Shintani H (2013) HPLC Separation of Amino Acids is Appropriate? Pharmaceut Anal Acta. 4: e158. doi: 10.4172/2153-2435.1000e158

Copyright: (c) 2013 Shintani H. This is an open-access article distributed under the terms of the Creative Commons Attribution License, which permits unrestricted use, distribution, and reproduction in any medium, provided the original author and source are credited. 